\title{
Protótipo de um glossário semibilíngue para alunos surdos ${ }^{1}$
}

\author{
Prototype of a semi-bilingual glossary for deaf students
}

\author{
Cristina Aparecida Bianchi de Souza GOMES* \\ Maria do Socorro Vieira COELHO**
}

\begin{abstract}
RESUMO: O artigo objetiva apresentar um protótipo de glossário semibilíngue para ser usado no ensino de Português como segunda língua para surdos -L2. O estudo foi desenvolvido com a participação de acadêmicos do 9º ano da Escola Bilíngue Libras Português Escrito de Taguatinga- Distrito Federal. Para tanto, utilizaram-se das abordagens teóricas básicas dos estudos linguísticos, com foco nas línguas de sinais. Contou-se, também, com o suporte teórico da Ciência do Léxico. Adotou-se a pesquisa-ação como metodologia para a constituição do corpus, para a seleção dos termos nos comandos de questões do livro didático Português: linguagens (São Paulo: Atual, 2014). Para a confecção do glossário proposto na pesquisa, utilizou-se, com adaptações, o Instrumento Genérico para Delimitação de Repertórios Léxico-Término-Fraseográfico. O repertório proposto é uma obra de cunho léxico-terminológico-pedagógico que visa a auxiliar o ensino de português como segunda língua. O glossário é composto por quarenta e três (43) lexias organizadas em quarenta e três (43) verbetes e

ABSTRACT: The article aims at presenting a prototype of a semi-bilingual glossary to be used in the teaching of Portuguese as a second language for deaf students-L2. The study was developed with the participation of students in the 9 o year of the Bilingual Written Portuguese Sign Language School in Taguatinga-Federal District. To achieve such a goal basic theoretical approaches in linguistics were used focusing on the sign language. Also, the theoretical support of the Lexicon Science was used. The methodology selected for the gathering of the corpus was the research-action, and for the choice of the terms in the commands of questions in the textbook Português: Linguagens (São Paulo; editors: Atual, 2014.) For the elaboration of the glossary proposed in the research the Generic Tool for the Delimitation of Word-Term-Sentence Repertoires was used but with some adaptations. The referred Repertoire is a pedagogical-terminological- lexicon book which aims at helping in the teaching of Portuguese as a second language. The glossary is composed by forty-three lexias (43) organized
\end{abstract}

\footnotetext{
${ }^{1}$ Esta pesquisa foi aprovada pelo Comitê de Ética sob o processo 49218615.2.0000.5146/UNIMONTES (1.321.864).

* Professora Mestre da Escola Bilíngue Libras e Português Escrito de Taguatinga - DF. ORCID: $\underline{\text { https://or- }}$ cid.org/0000-0003-29223753. cristinasbianchi@hotmail.com

** Professora do DCL - PPGMPLetras/Unimontes. Doutora em Língua Portuguesa pela PUCMinas. ORCID: https://orcid.org/0000-0002-3732-467X. soccoelho@hotmail.com
} 
está disponível no endereço https://glossariosemibilingue.wordpress.com

PALAVRAS-CHAVE: Léxico. Glossário. Ensino de português. LSB. Pessoas surdas. in forty-three (43) entries and is available at https://glossariosemibilingue.wordpress.com

KEYWORDS: Lexicon. Glossary. Teaching Portuguese. LSB. Deaf people.

\section{Introdução}

Objetivamos, neste texto, apresentar resultados do estudo ${ }^{2}$ cujo produto foi um glossário digital semibilíngue dos verbos que constituem os comandos de questões de um manual didático.

O glossário foi elaborado com os propósitos de incluir digitalmente os surdos e como apoio à aquisição e no uso da Língua Portuguesa (LP) escrita, segunda língua, com autonomia, ou seja, dispensando a frequente ajuda do professor, que geralmente não é fluente na Língua de Sinais Brasileira (LSB), e também do intérprete com conhecimento adequado de sinonímia para fornecer opções para os verbos citados nas instruções dos exercícios do livro didático em uso na escola que os surdos frequentam. Além disso, a pesquisa buscou oferecer subsídios didáticos aos professores que trabalham com o ensino de LP para estudantes surdos, principalmente aqueles que ainda não são nela fluentes.

O estudo foi desenvolvido com a participação de acadêmicos do $9^{\circ}$ ano da Escola Bilíngue Libras Português Escrito de Taguatinga, Instituição de ensino pública do Brasil que oferece metodologia direcionada para o ensino e a aprendizagem da Língua de Sinais Brasileira como primeira língua e a Língua Portuguesa como segunda língua. A língua de instrução nessa instituição é a LSB.

\footnotetext{
${ }^{2}$ Este texto foi escrito a partir da pesquisa feita por Gomes (2016).
} 
Consideramos o glossário fundamental para o consulente surdo, pois promove a inclusão digital e a conquista de certa autonomia pelos surdos em seus estudos, ameniza a necessidade de mediador em algumas situações, para explicar o significado de termos desconhecidos e oferece um instrumento de trabalho específico para realizar consultas e desenvolver estratégias de mediação em enquadres distintos, em sala de aula.

Nesse trabalho/glossário, apresentamos 43 verbetes, uma amostra de como o glossário pode se tornar fundamental para o estudante surdo na aprendizagem do português como Língua 2 (L2). Para que o surdo não dependa do mediador é necessário que esse glossário seja continuamente revisto e se expanda, abrangendo todos os vocábulos do livro didático.

\section{Considerações acerca da criação de glossário}

Dicionários, em sua maioria, são impressos, fato que pode dificultar seu acesso a qualquer aluno brasileiro, surdo, ou não, porque a escola, geralmente, nunca ensina ao aluno a fazer uso adequado deles. Além disto, em plena era digital e com tantos Ebooks disponíveis, os 'velhos' dicionários impressos vêm perdendo espaço paulatinamente cedendo lugar para a consulta rápida à Internet de quaisquer palavras ou informações, pelo menos nos grandes centros urbanos.

Indiscutivelmente, os indivíduos surdos têm capacidade de entender imagens estáticas, mas a língua deles é de predominância visual com movimentos. Essa é uma das principais característica da Língua de Sinais. Nessa língua, os sinais são realizados por 5 (cinco) parâmetros, Configuração de mão, Movimento, Ponto de Articulação, Orientação da Palma da Mão e Expressão Não Manual.

Em uma imagem estática, por exemplo, falta o movimento e isso poderá apresentar uma certa dificuldade na identificação da expressão não manual. Citamos, como ilustração, os sinais dos vocábulos cultura e inteligência. Esses são representados com 
a mesma configuração de mão, mesmo ponto de articulação e a mesma orientação da palma da mão, no entanto, o movimento é diferente. Um se movimenta da testa para cima, cultura, e o outro de cima para testa, inteligência. Em relação às expressões não manuais, podemos citar os sinais dos vocábulos laranja e sábado. Esses são realizados com a mesma configuração de mão, o mesmo ponto de articulação e movimento, mas a expressão não manual é diferente. O primeiro faz um movimento 'com a boca de sugar', enquanto o segundo, sábado, não há essa expressão. Isso não fica claro numa imagem estática.

Diante do exposto, um glossário digital é de suma relevância para a aquisição de conhecimentos pelas pessoas surdas, porque vídeos/imagens estão em movimento e, assim, oferecem possibilidades para o aluno surdo entender os sinais reproduzidos. É importante reiterar, ainda, que, no mercado editorial, não encontramos, durante a pesquisa, livros didáticos destinados exclusivamente ao público surdo.

Nas escolas públicas do Distrito Federal, localidade em que desenvolvemos esta pesquisa, o professor de aluno surdo, na área de Língua Portuguesa, não dispõe de material algum oferecido pelo Ministério da Educação (MEC), para a preparação de suas aulas. Os livros didáticos disponibilizados pelo MEC atendem tão somente aos alunos ouvintes e, assim, os conhecimentos linguísticos são, em parte, sonegados aos estudantes surdos.

Encontramos algumas obras lexicográficas/terminológicas que têm como objetivo fornecer sinal correspondente para uma palavra ou um termo da língua oral, mas que não são utilizados em sala de aula, por não possuírem caráter pedagógico. Assim sendo, o aprendiz surdo de Português como segunda língua não tem acesso à linguagem referencial dos verbos encontrados no corpo de comandos de questões de livros didáticos.

Decerto, com esse glossário podemos contribuir para o ensino e a aquisição da Língua Portuguesa de alunos surdos com subsídios e estratégias específicos. Além 
disso, oferecemos um protótipo de glossário semibilíngue contextualizado que poderá e deverá ser revisto e ampliado. Portanto, este trabalho justifica-se por seu ineditismo e por ser um estudo realizado em um locus no qual uma minoria linguística, o aprendiz surdo, usufruirá da elaboração de um glossário, tendo, assim, mais um recurso-apoio didático para ampliar seu léxico da Língua Portuguesa.

Elaboramos o glossário digital semibilíngue em LSB e Língua Portuguesa, a partir da compilação, em ordem alfabética, dos verbos que compõem os comandos das questões da seção Estudo de Texto: Compreensão e Interpretação, do livro didático Português: Linguagens, de autoria de Cereja e Magalhães (2014), cuja capa apresentamos na figura 1 , a seguir.

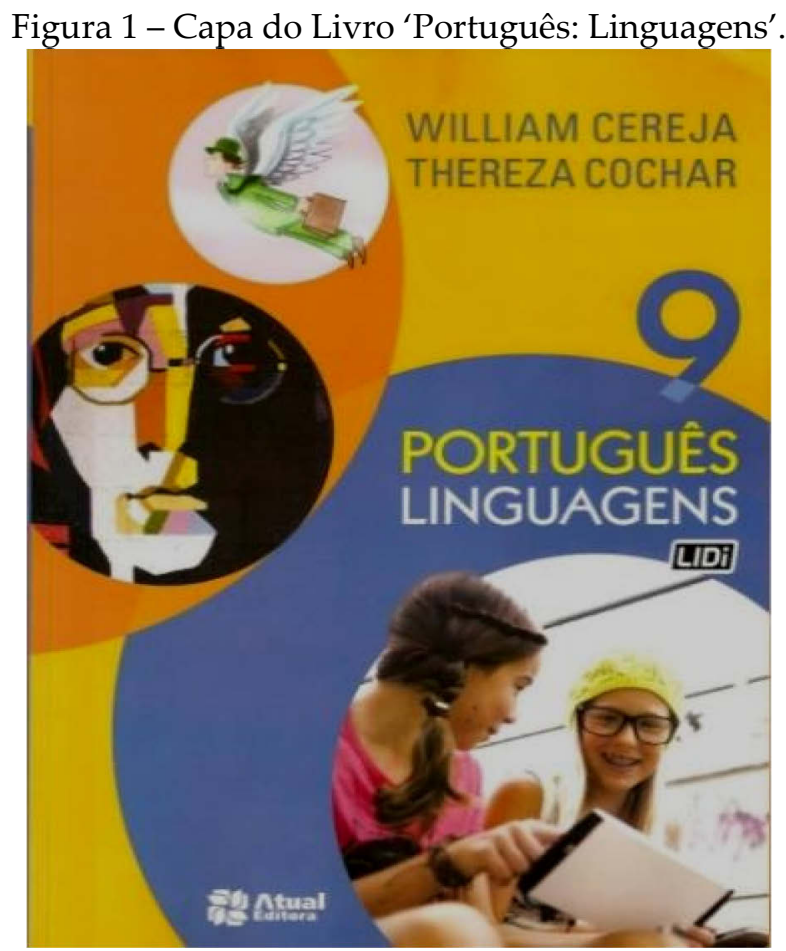

Fonte: Cereja e Magalhães (2014).

Para tanto, utilizamos as abordagens teóricas da Linguística Aplicada (LA), fundamentadas em Almeida-Filho (2011). A Linguística Aplicada é uma das três áreas das ciências da linguagem e possui um caráter transdisciplinar, interagindo com outras áreas do conhecimento, como a Filosofia, Tradução, Análise do Discurso, entre 
outras. Tem como objeto de investigação questões da linguagem e sua prática social, apresentando interesse por variados temas que envolvem o uso de língua materna, o ensino de segunda língua e o das línguas de contato. Não podemos conceber o foco de pesquisa da LA como, simplesmente, uma teoria linguística que visa a encontrar soluções para o ensino de uma língua, seja ela a Língua um (L1) ou a Língua dois (L2), mas, sim, como uma ciência que, segundo Almeida Filho (2011, p. 32), pode (re)formular teorizações sobre o cerne específico da composição e do funcionamento do processo de aprender língua e, eventualmente, subsidiar com contribuições relevantes de outras áreas do conhecimento também voltadas para a prospecção de conhecimentos teóricos da prática social efetiva do linguajar.

O trabalho da LA tem como referencial principal a linguagem e, diante de tantas definições que possui, foi necessária uma triagem criteriosa para chegarmos àquela que utilizamos em nossa pesquisa. Recorremos às abordagens teóricas básicas dos estudos linguísticos, com foco nas línguas de sinais, segundo Quadros (2004), Nascimento (2009) e Brito (2010), pois a Língua de Sinais pertence à modalidade espaçovisual, isto é, as relações entre os elementos se dão por meio do uso do espaço, na sintaxe, na morfologia e na fonologia e, segundo Ferreira (2010, p. 11), “é uma língua natural com toda a complexidade que os sistemas linguísticos que servem à comunicação e de suporte de pensamento às pessoas dotadas da faculdade de linguagem possuem". Portanto, LSB é uma língua como qualquer outra, no entanto, sua formação se dá diferentemente da das línguas orais.

Contamos, também, com o suporte teórico da Ciência do Léxico, de Biderman (2001a, 2001b), Krieger e Finatto (2004) e Isquerdo e Finatto (2010).

Como metodologia de pesquisa, utilizamos a pesquisa-ação proposta em Engel (2000) e Tripp (2005). Essa proposta metodológica, segundo Engel (2000, p. 182), [...]" procura unir a pesquisa à ação ou prática, isto é, desenvolver o conhecimento como parte da prática". Nossa pesquisa parte de observações realizadas dentro de 
salas de aula em que o aluno surdo não tem acesso linguístico ao livro didático, porque o livro é elaborado para o ensino de português como Língua 1 (L1). Por isso, por meio do glossário proposto, procuramos intervir no processo de ensino e aprendizagem do português como segunda língua, pois, conforme Engel (2000, p. 182), a pesquisa-ação deve $[\ldots]$ “.intervir na prática de modo inovador já no decorrer do próprio processo de pesquisa e não apenas como possível consequência de uma recomendação na parte final do projeto". Essa metodologia tem características próprias que a diferenciam das demais, conforme destaca Tripp (2005, p. 447): “A pesquisa-ação requer ação tanto nas áreas da prática quanto da pesquisa, de modo que, em maior ou menor medida, terá características tanto da prática rotineira quanto da pesquisa científica".

Além disso, para a confecção do glossário proposto na pesquisa, utilizamos, com adaptações, o Instrumento Genérico para Delimitação de Repertórios Léxico-Término-Fraseográfico, de acordo com a proposta de Nascimento (2006).

\subsection{Macroestrutura}

O repertório proposto é uma obra de cunho léxico-terminológico-pedagógico que visa a auxiliar o ensino de português como segunda língua. Foi elaborado por meio de consultoria na área de LSB, de criação e gravação dos sinais por estudantes surdos da Escola Bilíngue Libras e Português Escrito de Taguatinga. Os consulentes são falantes da língua-alvo, LSB, e cursam o $9^{\circ}$ ano das séries finais do ensino fundamental. A língua de entrada está na modalidade oral-auditiva, LP escrita, e as demais informações do glossário estão em LSB. É um glossário, reiteramos, especializado e voltado para o ensino do português como segunda língua.

A seleção dos termos foi feita nos comandos de questões do livro didático, na seção de interpretação de texto. Para a escolha dos verbos, fizemos uma seleção de comandos de questões; na sequência, retiramos os verbos que compõem os comandos de questões do livro didático, com exceção dos verbos de ligação. Depois dessa seleção, 
desenvolvemos uma pesquisa em dois dicionários de LSB, nos quais procuramos detectar se o verbo já estava lexicografado. Em seguida, os verbos foram apresentados aos estudantes surdos para dizerem quais deles eles conheciam.

Para a composição desse glossário, optamos por selecionar somente termos não lexicografados. Os verbetes são dispostos em ordem alfabética e cada um deles é apresentado por uma ficha léxico-terminográfica apresentada no Quadro 1, na seção 2.3, a seguir. Há quatro contextos: Configuração de Mão, lexia e mecanismo de busca. O glossário tem formato eletrônico e pode ser encontrado no endereço <https://glossariosemibilingue.wordpress.com/>.

Os vídeos gravados estão hospedados no site de compartilhamento de vídeos vimeo (<www.vimeo.com>). Utilizamos essa plataforma Vimeo somente para a locação dos vídeos ${ }^{3}$, para que, posteriormente, fossem usados no site como ilustração. Após a análise do projeto do glossário semibilíngue, optamos por essa plataforma pelos seguintes motivos: a) ser um site de upload e compartilhamento de vídeos muito conhecido entre os produtores de audiovisual e por poder ser usado pelos leigos ou pelos que possuem conhecimentos avançados nessa tecnologia. Seu acervo de vídeos é considerado de alta qualidade, reunindo trabalhos premiados no mundo todo; b) possuir uma versão basic (gratuita) que atende a todas as necessidades do projeto: limite de upload de 500 MB por semana, ou 26 GB por ano para o usuário comum. Faz parte de uma comunidade de mídias criativas e com um público atento à qualidade do que é exibido; c) ter a possibilidade de ajustar o tamanho da janela, definir reprodução automática, ativar repetição (loop), inserir definição abaixo do vídeo, entre outras opções de manuseio. É possível ajustar várias qualidades, até a mais alta, de 1080p, e também deixar no automático, dependendo da conexão do usuário com a Internet. É possível disponibilizar o vídeo para download; e, por fim, d) por possuir uma ferramenta que

\footnotetext{
${ }^{3}$ Os vídeos são de acesso restrito às pesquisadoras.
} 
indica quantas vezes um vídeo foi visualizado e compartilhado, além de mostrar essas estatísticas em um gráfico acumulado diário.

A apresentação dos vídeos é feita por meio de código de incorporação e está hospedada no site $<$ www.glossariosemibilingue.wordpress.com.br $>$. O site é desenvolvido com a tecnologia WordPress, um aplicativo de sistema de gerenciamento de conteúdo para web escrito em PHP, com banco de dados MySQL voltado, principalmente, para a criação de sites e blogs via web. É um software livre. Fizemos uma customização para adaptá-lo às características exigidas pelo glossário semibilíngue. O site está hospedado com uma conta gratuita no servidor de hospedagem www.wordpress.com.

\subsection{Microestrutura}

A entrada poderá ser feita de quatro maneiras: ou pelo contexto, ou pela Configuração de Mão, ou pela lexia, ou pelo mecanismo de busca. Em um primeiro momento, tínhamos pensado em adotar uma dessas definições: lexicográfica, enciclopédica ou terminológica, mas, durante o desenvolvimento desta pesquisa, dois motivos nos levaram a optar por não colocar uma definição, mas um equivalente. O primeiro foi durante o processo de intervenção, em que os alunos, por iniciativa própria, procuravam informações nos dicionários online disponíveis em seus celulares, para entenderem melhor o significado da palavra para a elaboração do glossário, e não encontravam um significado que correspondesse ao do contexto do comando. O segundo momento foi quando pesquisamos nos dicionários definições linguísticas para os termos e constatamos que não havia definições precisas que contemplassem o significado do termo em seu contexto. Então, optamos por colocar um significado equivalente, porque atingiria o nosso objetivo e seria mais sucinto e direto para nosso aluno. 


\subsection{Elaboração da ficha léxico-terminográfica}

Para a confecção das quarenta e três (43) fichas léxico-terminográfico-terminológicas, utilizamos as propostas de Faulstich (2001) e de Lima (2014), com adaptações para a realidade de nossos consulentes, os alunos surdos do $9^{\circ}$ ano do ensino fundamental. Vejamos o modelo a seguir.

Quadro 01 - Modelo da ficha léxico-terminográfica.

\begin{tabular}{|l|l|}
\hline $\begin{array}{l}1 \text { - Glossário Semibilíngue digital em Língua de Sinais Brasileira e Por- } \\
\text { tuguês: Comandos de questões do livro didático }\end{array}$ & № \\
\hline 2 - Termo: \\
\hline 3 - Contexto: \\
\hline 4 - Equivalente: \\
\hline 5 - Foto(s) do sinal: \\
\hline 6 - Remissiva: \\
\hline 7 - Quantidade de mãos: \\
\hline 8 - Configuração de mão: \\
\hline 9 - Movimento: \\
\hline 10 - Expressão facial: \\
\hline 11 - Referência: \\
\hline
\end{tabular}

Fonte: Elaborado pelas autoras.

A seguir, especificamos cada campo dessa ficha.

1. Título da ficha - indica o nome do projeto em questão. $\mathrm{N}$ - indica o número de registro da ficha.

2. Termo - indica o nome do verbo em LP que será analisado. O verbo aparece no infinitivo.

3. Contexto - texto que se refere ao comando da questão do livro didático de que retiramos o corpus de nossa pesquisa.

4. Equivalente - indica outro verbo em LP que possua um valor semântico equivalente ao do termo. 
5. Foto(s) do sinal - mostra(m) a(s) foto(s) que indica $(m)$ a realização do sinal.

6. Remissiva - indica outro sinal que possua uma relação léxico-semântica com o termo.

7. Quantidade de mão - indica quantas mãos estão envolvidas no sinal.

8. Configuração de mão - mostra que configurações de mão são utilizadas para aquele sinal.

9. Movimento - indica se o sinal tem movimento ou não.

10. Expressão facial - indica se o sinal apresenta ou não expressão facial.

11. Referência - indica o nome do livro didático e a página de onde foi retirado o corpus da pesquisa.

Na próxima seção, apresentamos as fichas léxico-terminográficas que preenchemos para a confecção do glossário.

\section{Fichas léxico-terminográficas}

Organizamos as fichas léxico-terminográficas em duas fases. A primeira fase reuniu os sinais dados pelos discentes, durante o estudo realizado sobre os comandos das questões do livro didático. Esta etapa iniciou-se com a leitura pelos alunos dos comandos das questões em Língua Portuguesa; após essa leitura, lemos em LSB coletivamente e, simultaneamente, esclarecíamos as dúvidas apresentadas pelos estudantes em relação às palavras do texto, que eles não entendiam ou não conheciam. Os alunos discutiam entre eles e, às vezes, com o auxílio do dicionário de Língua Portuguesa, qual seria o sinal que poderia ser dado para aquela lexia. Depois dessa discussão, eles nos apresentavam o sinal. Durante esse processo, tentamos não interferir, exceto nos casos extremos em que não havia nenhuma coerência entre o sinal apresen- 
tado em LSB e a palavra em LP. Explicávamos, novamente, o contexto em que a palavra estava inserida, para que eles percebessem que o sinal não estava adequado e nos apresentassem o sinal devido.

Em uma segunda fase foi feito o processo de intervenção, pois notamos que os sinais gravados primeiramente não condiziam com o sentido do contexto apresentado. Então, os sinais dados pelos alunos do $9^{\circ}$ ano foram validados pelos alunos do $3^{0}$ ano. No entanto, depois de uma análise criteriosa, percebemos que os sinais ainda não condiziam com o contexto do livro didático. Identificamos essa inadequação e propusemos, junto com uma professora surda e proficiente em LSB, o estudo dos comandos das questões do livro didático, para que fossem novamente criados novos sinais. Para tanto, retornamos todos à sala de aula e, orientados pela professora surda e também por nós, fizemos um novo estudo dos comandos das questões do livro didático, para que os alunos nos dessem os sinais para aquelas lexias que consideramos erradas. Depois de realizado esse estudo orientado, os estudantes nos apresentaram sinais adequados ao sentido do contexto em que eles estavam inseridos. Gravamos tais sinais e solicitamos a validação da professora surda supracitada.

\subsection{Fichas léxico-terminográficas - fase 1}

Nesta subseção, apresentamos uma das quarenta e três (43) fichas léxico-terminográficas como modelo. Elas são compostas por quarenta e três (43) lexias organizadas em quarenta e três (43) verbetes, que foram utilizados para a confecção do Glossário semibilíngue digital Língua de Sinais Brasileira e Português: comandos de questões do livro didático. Os sinais dessas fichas foram dados pelos alunos surdos do $9^{\underline{0}}$ ano da Escola Bilíngue Libras e Português Escrito de Taguatinga, mediante um processo de estudo dos comandos do livro didático que foi realizado por meio de discus- 
sões em LSB e em LP e, ao término desse estudo, os alunos deram sinais contextualizados para as lexias apresentadas que, logo após, foram validados pelos alunos surdos do $3^{\mathbf{o}}$ ano, sinais estes que apresentamos, a seguir.

Quadro 2 - Exemplo de Ficha terminográfica preenchida.

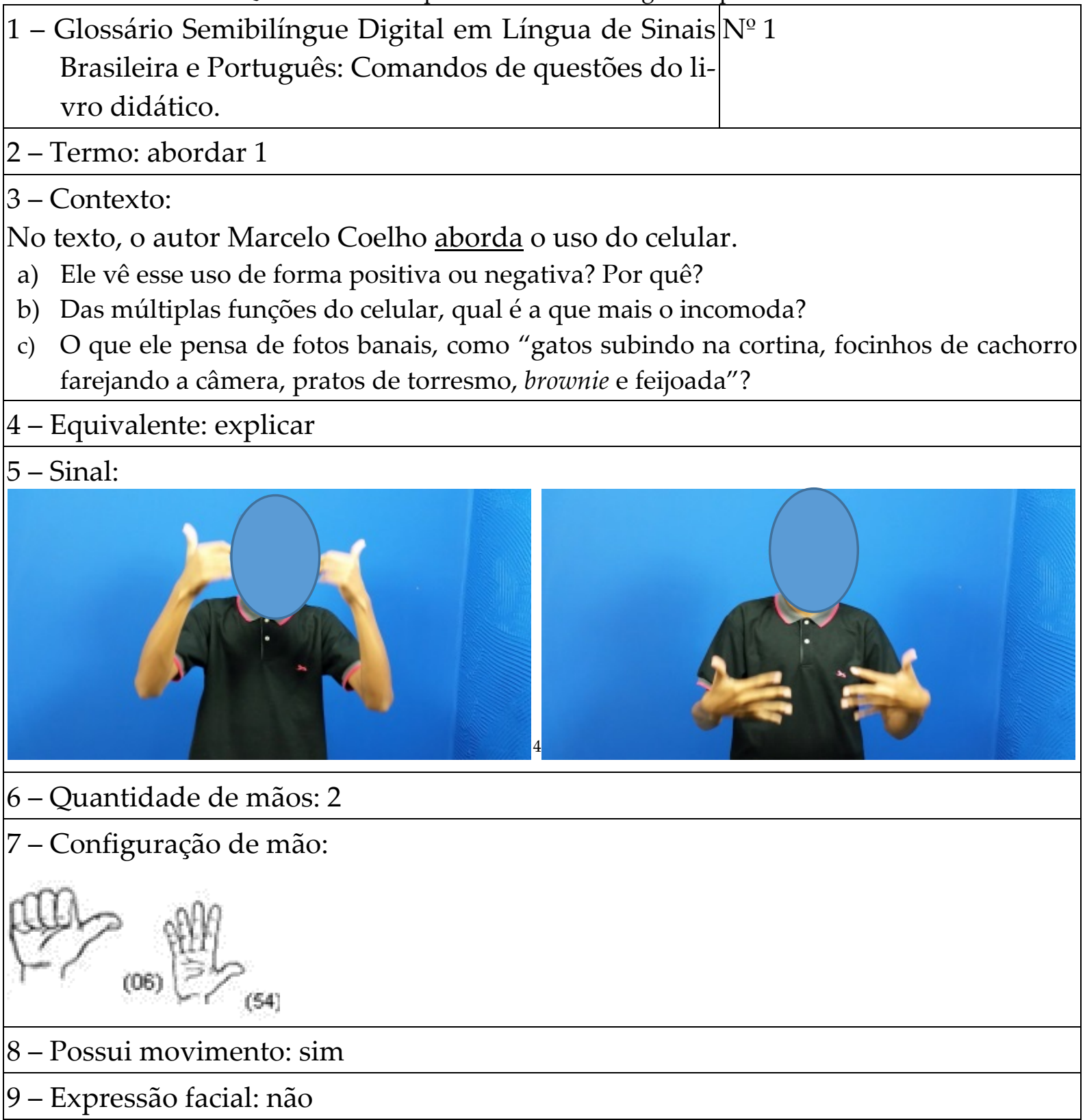

\footnotetext{
${ }^{4}$ Informamos que as imagens das pessoas apresentadas neste texto foram autorizadas mediante assinatura dos termos de consentimento livre e se encontram com as pesquisadoras.
} 
10 - Referência: CEREJA, Roberto William; MAGALHÃES, Thereza Cochar. Português: linguagens. São Paulo: Atual, 2014. p. 16.

Fonte: elaborado pelas autoras.

\section{Glossário léxico-terminográfico semibilíngue}

Nesta seção, apresentamos o Glossário semibilingue digital em Língua de Sinais Brasileira e Língua Portuguesa: comandos de questões do livro didático. Este material didático, produto de uma pesquisa, é composto por 43 (quarenta e três) lexias organizadas em 43 (quarenta e três) verbetes e está localizado no endereço https://glossariosemibilingue.wordpress.com/. O glossário está dividido nas seguintes abas: apresentação, proposta, contexto, lexias, ajuda e contato.

a) A aba Apresentação é constituída de três partes: nome da pesquisa (Proposta para o ensino de Língua Portuguesa como segunda língua: glossário semibilingue digital em Língua Sinais Brasileira e Língua Portuguesa), capa do livro usado no estudo e apresentação do glossário em LSB. Exemplificamos, com a (cf. Figura 2).

Figura 2 - Aba da apresentação. 
APRESENTAÇÄO / PROPOSTA / CONTEXTO / LEXIAS / AJUDA / CONTATO

\section{Apresentação}

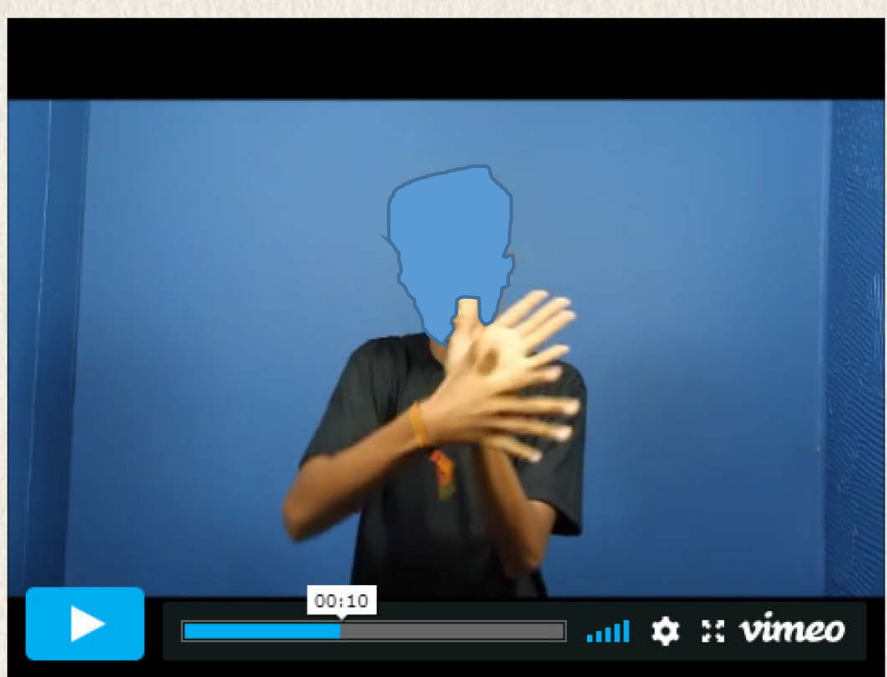

\section{Pesquisa}

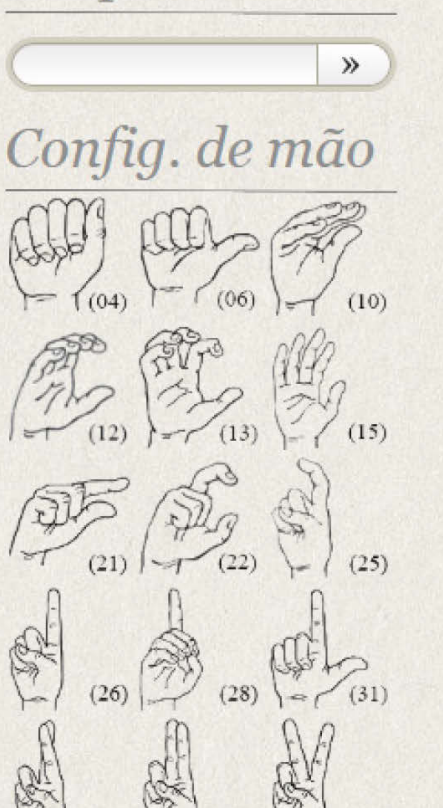

Fonte: https://glossariosemibilingue.wordpress.com/. Acesso em: 22 maio. 2019.

b) A aba Proposta traz informações sobre como foi elaborado o glossário: estruturas macro e micro, colaboradores/consultores, dissertação.

\footnotetext{
A aba proposta dá uma visão geral de como foi elaborado o glossário. Está dividido em três seções: a primeria apresenta a justificativa para a criação do glossário, os objetivos que almejávamos alcançar, a argumentação teórica que foi utulizada para dar sustentação, o público-alvo que se beneficiará dessa investigação, e, por fim, os resultados que já alcançamos com o glossário. A segunda seção aborda a estrutura macro e micro do glossário. Na terceira seção intitulada coloboradores e consultores, damos os créditos aos demais participantes desse trabalho, a saber: os alunos participantes, os consultores nas areas de Língua de Sinais Brasileira, de lexicográficałterminologia, de informática, e, por fim, os colaboradores das filmagens.
} 
c) A aba Contexto traz os comandos de questões do livro didático que foram selecionados, por exemplo:

\section{Adentrar \\ (Adentra)}

No mundo encantado em que Alice adentra, ela ora cresce, ora encolhe, ora fica em seu tamanho normal. Diz o narrador, no 10ํㅜ parágrafo: "Não se desespere ao triste pensamento de Alice: 'Devo estar diminuindo de novo'. Em algum lugar, há cogumelos que nos fazem crescer novamente". Referência: CEREJA; MAGALHÃES (2014, p. 192).

d) A aba Lexias traz uma listagem das lexias em vídeos que compõem o glossário (cf. Figura 3).

Figura 3 - Realização da lexia adentrar em LSB.

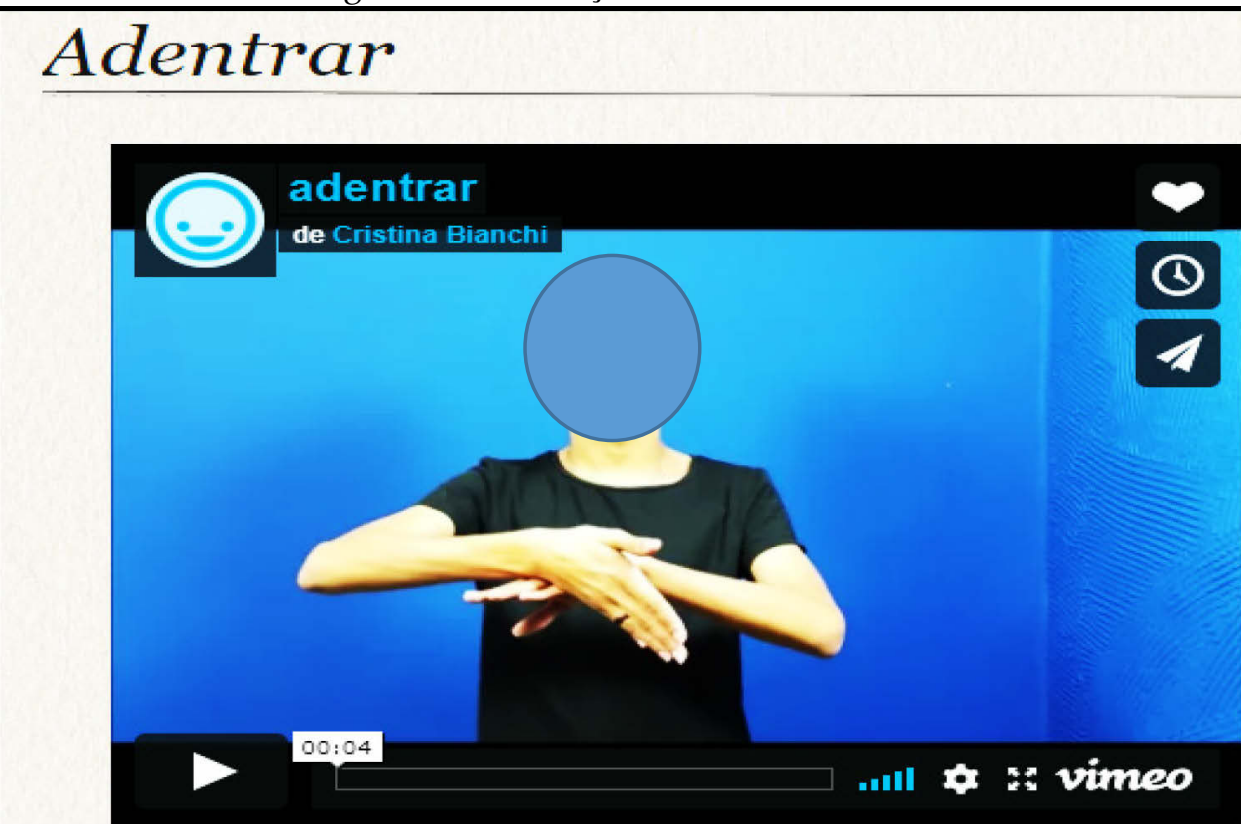

Equivalente: Penetrar, entrar 
Fonte: https://glossariosemibilingue.wordpress.com/. Acesso em: 22 maio 2019.

e) A aba Ajuda traz informações de como utilizar o glossário em LSB. Vejamos:

Essa aba é composta de 05 seções: apresentação, proposta, contexto, lexia e contato. Cada seção possui um vídeo explicativo em LSB esclarecendo como o estudante pode utilizar o glossário. Esse canal foi elaborado exclusivamente para alunos surdos usuários de LSB.

f) A aba Contato é um canal de comunicação entre o usuário e as pesquisadoras. Citamos, a seguir, um exemplo como ilustração.

Nesse espaço é possível a quaisquer usuários do glossário entrar em contato com as pesquisadoras. Os campos para serem preenchidos pelo consulente são: contato, nome, e.mail, website e comentário, sendo que não é obrigatório preencher o penúltimo.

O glossário semibilíngue digital possibilita a consulta de quatro maneiras: contexto, configuração de mão, lexia e pelo modo pesquisa. A entrada é feita por ordem alfabética. Para se pesquisar pelo contexto, devem-se seguir alguns passos:

1. Clicar na aba Contexto: abrirá uma janela com as letras do alfabeto. (cf. Figura 4). Figura 4 - Aba do contexto com as letras do alfabeto.

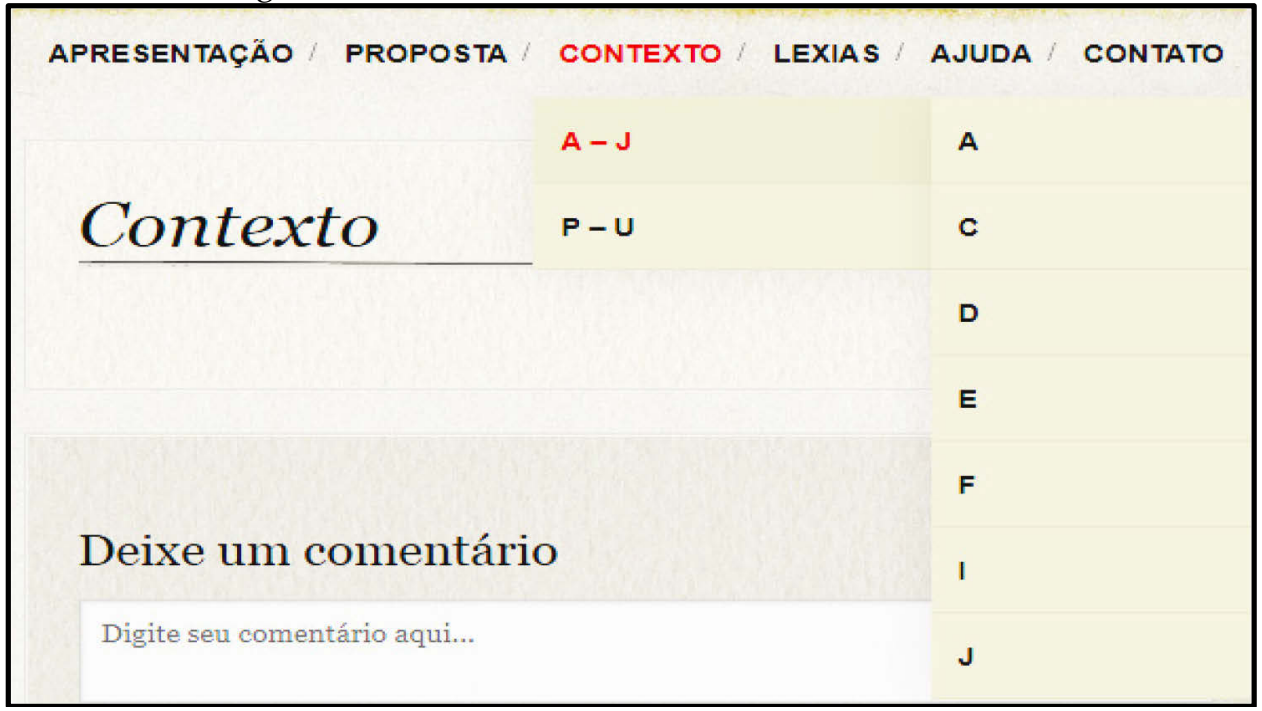


Fonte: https://glossariosemibilingue.wordpress.com. Acesso em: 22 maio 2019.

2. Clicar na letra inicial da palavra a ser pesquisada. Aparecerá uma nova janela com uma lista de todas as lexias que se iniciam com aquela letra (cf. Figura 5), a seguir.

Figura 5 - Aba do contexto com as lexias iniciadas com a letra "a".

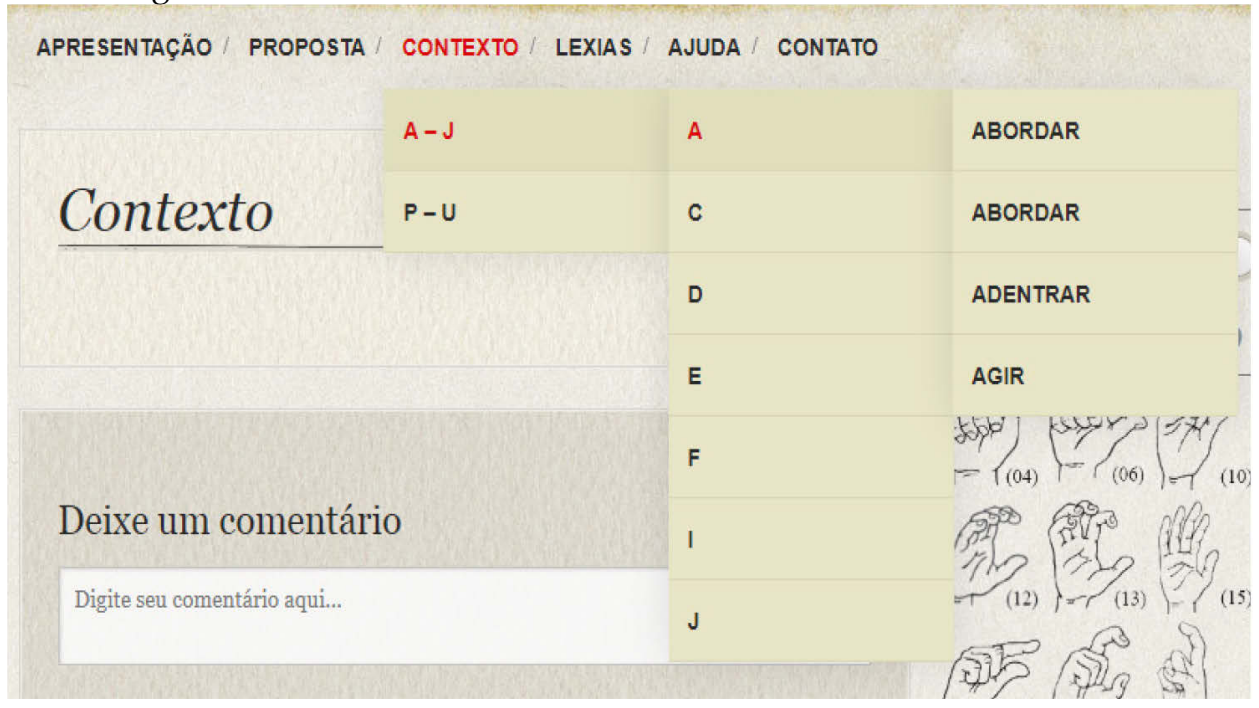

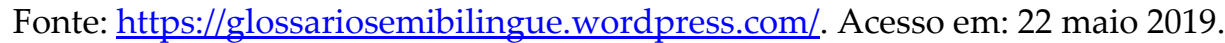

3. Clicar na palavra desejada: aparecerá automaticamente o comando da questão. Dentro do texto da questão, o verbo estará em vermelho. Basta clicar no verbo para abrir uma janela com o vídeo do referido vocábulo (cf. Quadro 3 e Figura 6).

Quadro 3 - Comando da questão com o verbo em destaque.

Abordar

( Aborda)

No texto, o autor, Marcelo Coelho aborda o uso do celular.

a- Ele vê esse uso de forma positiva ou negativa? Por quê?

b- Das múltiplas funções do celular, qual é a que mais incomoda?

c- O que ele pensa de fotos banais como " gatos subindo na cortina, focinhos de cachorro farejando a câmera, pratos de torresmos, bronwie e feijoada" ?

Referência: CEREJA, Roberto Willian: MAGALHÃES, Thereza Cochar. Português linguagens. São Paulo: ATUAL, 2014. p. 16

Fonte: https://glossariosemibilingue.wordpress.com. Acesso em: 22 maio 2019. 
Figura 6 - Imagem do verbo sinalizado.

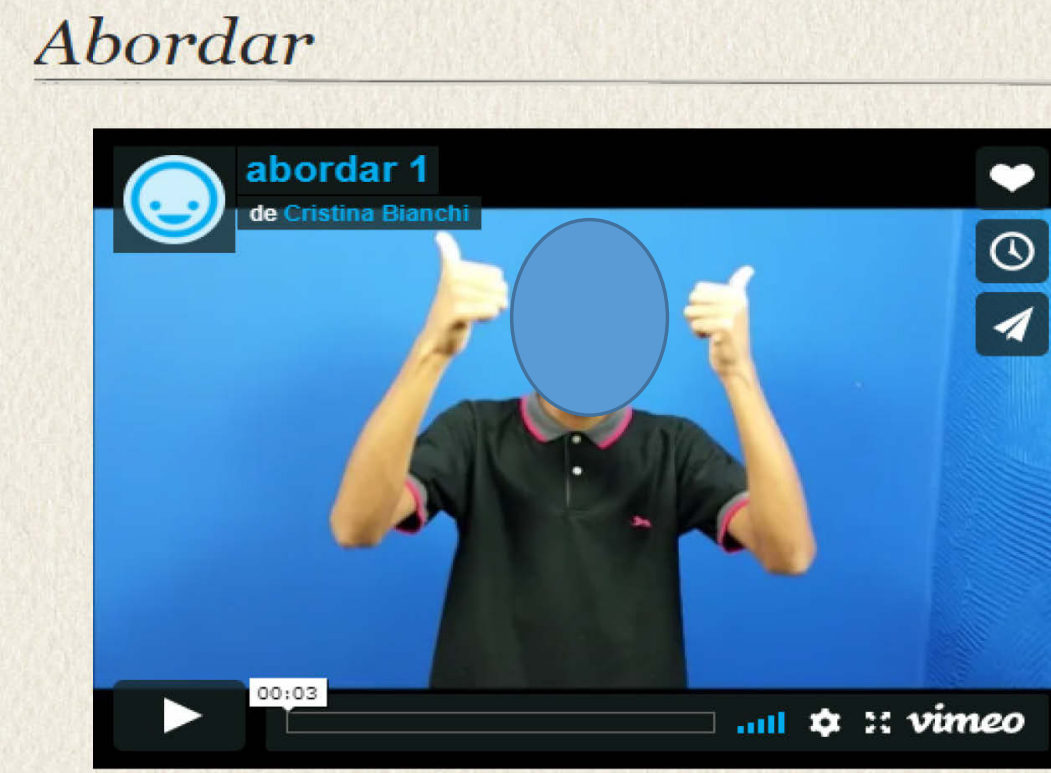

Equivalente : explicar

Irpara o contexto.

abordar 1 from Cristina Bianchi on Vimeo.

Fonte: https://glossariosemibilingue.wordpress.com/. Acesso em: 22 maio 2019.

Para a pesquisa pela Configuração de Mão, o usuário deve escolher a configuração de mão desejada e, ao clicar, aparecerá uma janela que terá os seguintes passos, propostos por Gomes, 216, p. 181:

1. Clicar na configuração de mão desejada. Aparecerá uma janela com todas as informações que possuem para aquela configuração de mão.

2. Na janela, aparecerá(ão) a(s) lexia(s) correspondente(s) à configuração de mão. Na frente, haverá os seguintes itens: sinal, contexto e tudo. Basta o consulente clicar na opção desejada e abrirá uma nova janela com as informações (cf. Figura 7).

Figura 7 - Pesquisa pela configuração de mão ${ }^{5}$

${ }^{5}$ Fonte: https://glossariosemibilingue.w. Acesso em: 22 maio 2019. 


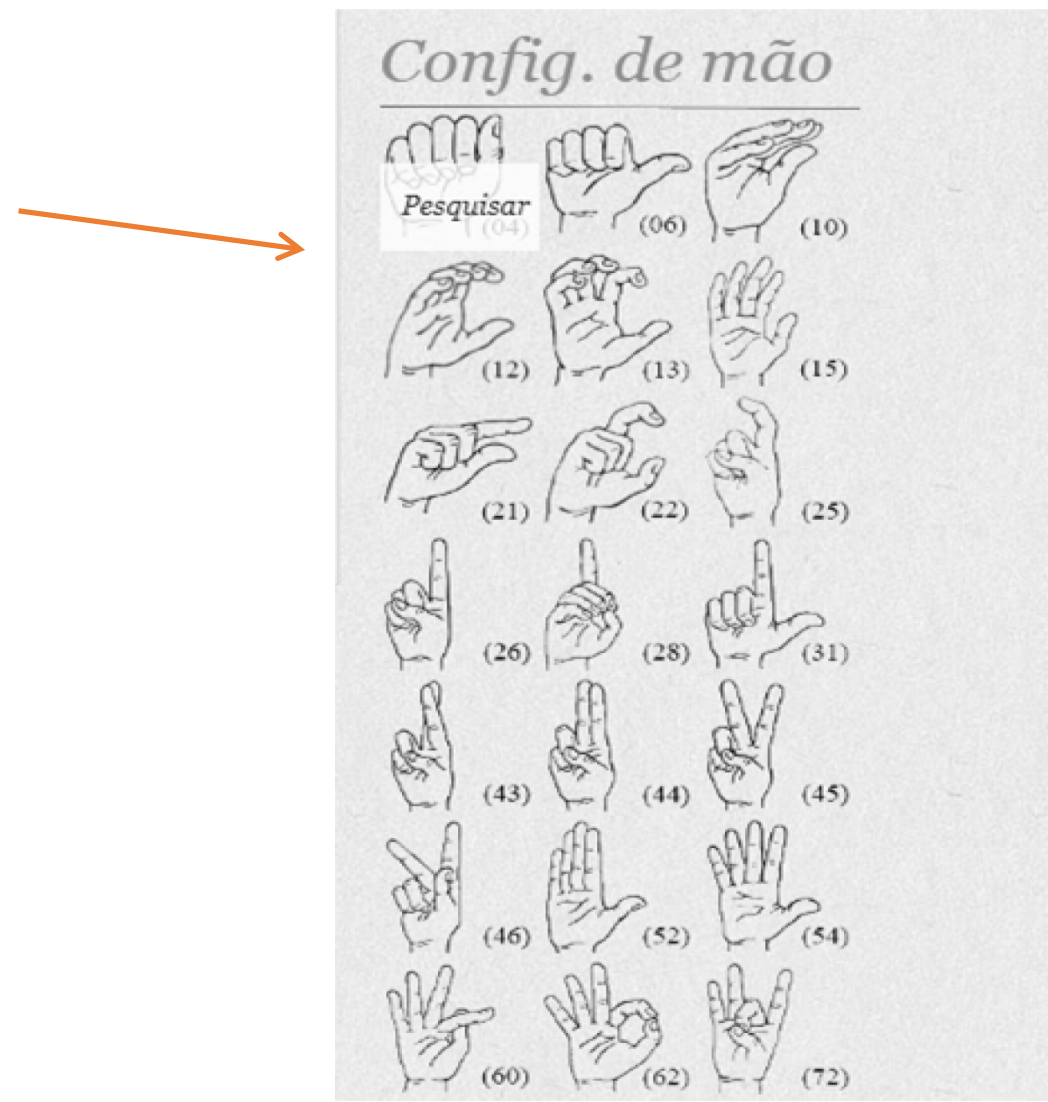

Fonte: https://glossariosemibilingue.wordpress.com/. Acesso em: 22 maio 2019.

3. Na janela, aparecerá(ão) a(s) lexia(s) correspondente(s) à configuração de mão e, na frente, haverá os seguintes itens: sinal, contexto e tudo. O consulente clicará na opção desejada e abrirá uma nova janela com as informações (cf. Figura 8) apresentada em seguida.

Figura 8 - Exemplo de resultado da busca pela configuração de mão.
APRESENTAÇÄO
PROPOSTA
CONTEXTO
LEXIAS
AJUDA
CONTATO

\section{Configuração de mão 10}

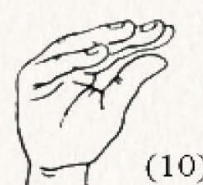

Foram encontrados 02 verbos com essa configuração de mão. Escolha sinal, contexto ou tudo para dar continuidade à pesquisa:

(10)

\begin{tabular}{|c|c|c|c|}
\hline Percorrer & $\underline{\text { sinal }}$ & contexto & $\underline{\text { tudo }}$ \\
\hline Postar & sinal & contexto & tudo \\
\hline
\end{tabular}


Fonte: https://glossariosemibilingue.wordpress.com/. Acesso em: 22 maio 2019.

Para a busca pela lexia, basta clicar na aba Lexias. Automaticamente, aparecerá uma série de vídeos com os sinais. Basta o usuário escolher qual o verbo que deseja ver (cf. Figura 9).

Figura 9 - Exemplo da entrada pela aba Lexia.

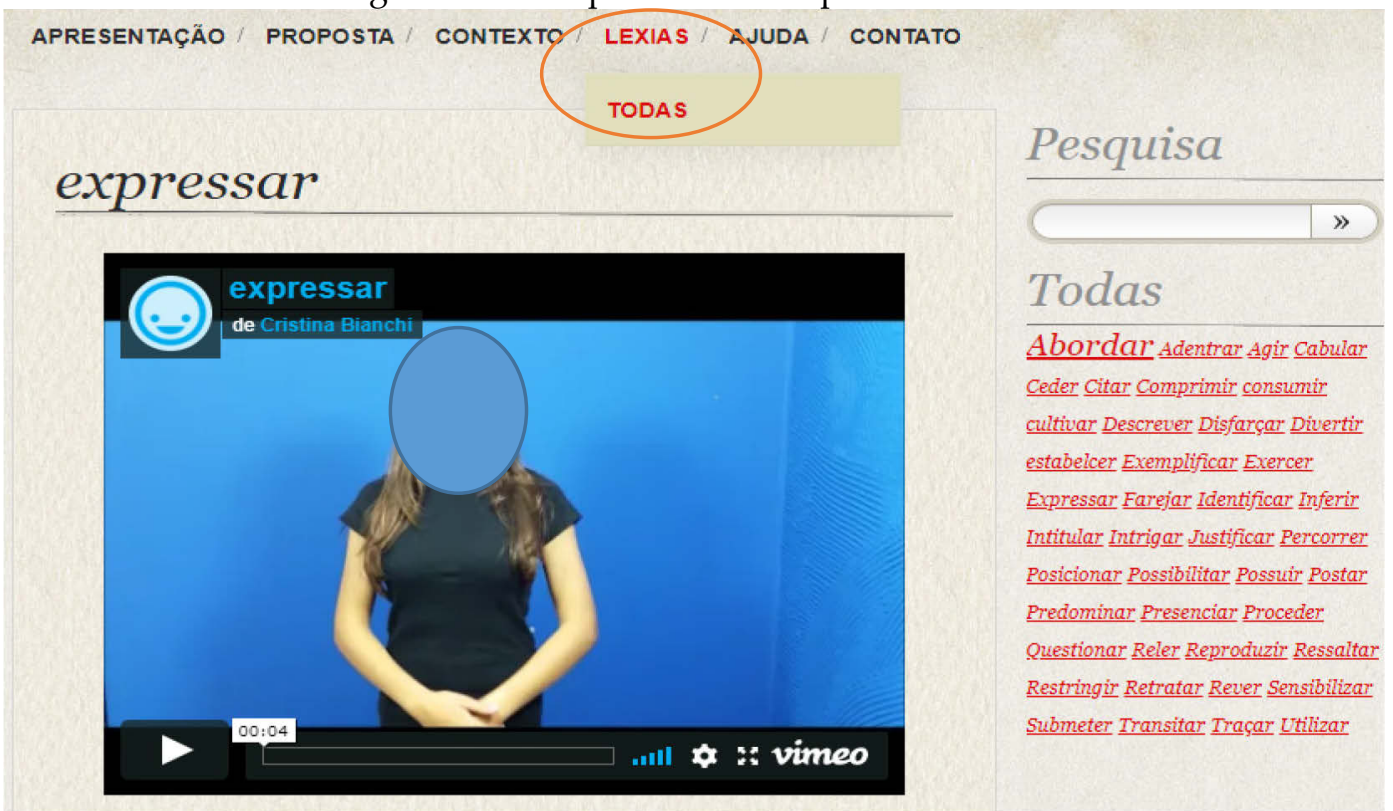

Fonte: https://glossariosemibilingue.wordpress.com/. Acesso em: 22 maio 2019. 
Para procurar pela aba Pesquisa, basta o usuário digitar, na caixa de diálogo lexia desejada e clicar na seta dupla para abrir uma janela com o vídeo do sinal desejado (cf. Figura 10) e logo aparecerá o vídeo sinalizado da lexia em LSB (cf. Figura 11).

Figura 10 - Mecanismo de busca pelo ícone de pesquisa.

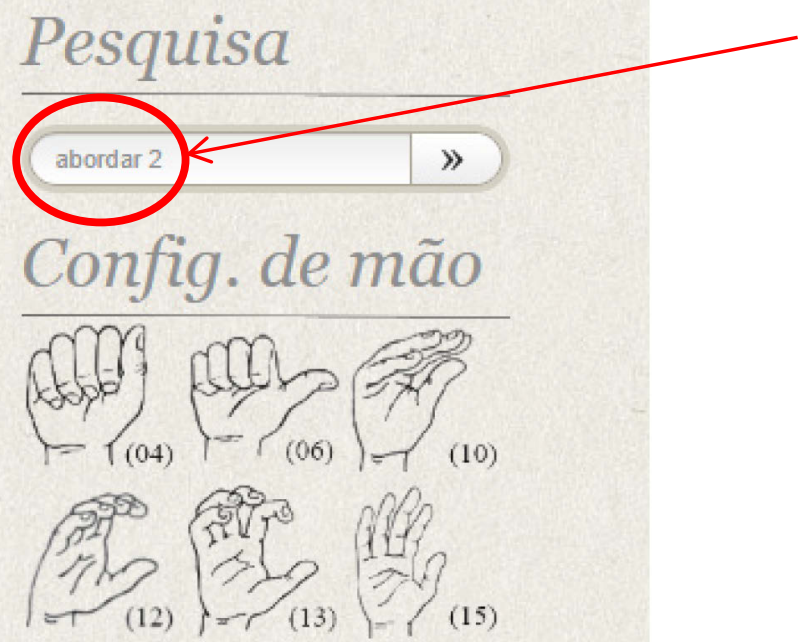

Fonte: https://glossariosemibilingue.wordpress.com/. Acesso em: 22 maio 2019.

Figura 11 - Exemplo de busca da unidade lexical pela aba Pesquisa.

APRESENTAÇÃo PROPOSTA CONTEXTO LEXIAS AJUDA CONTATO

RESULTADOS DA BUSCA PARA: "ABORDAR 2"

Abordar 2

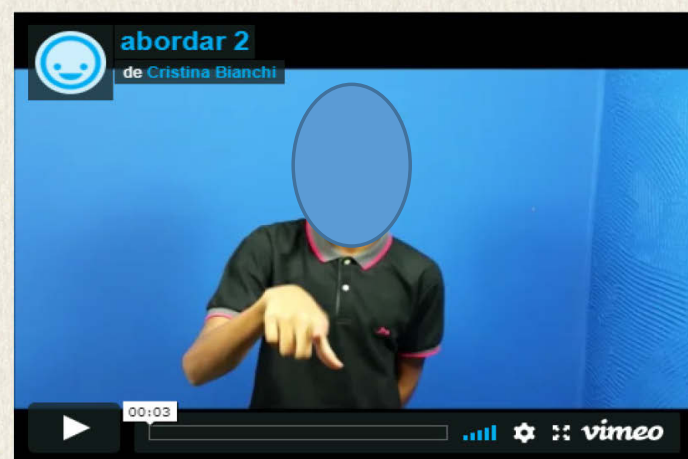

Fonte: https://glossariosemibilingue.wordpress.com/. Acesso em: 22 maio 2019. 
O verbete do glossário é composto das informações: Termo em LP - Sinal do termo em LSB - Equivalente em LP - Remissiva dos sinais na LSB (quando houver) - Contexto. Estruturamos o verbete conforme a cf. Figura 12 a seguir.

Figura 12 - Exemplo de verbete.

\section{Exemplificar}

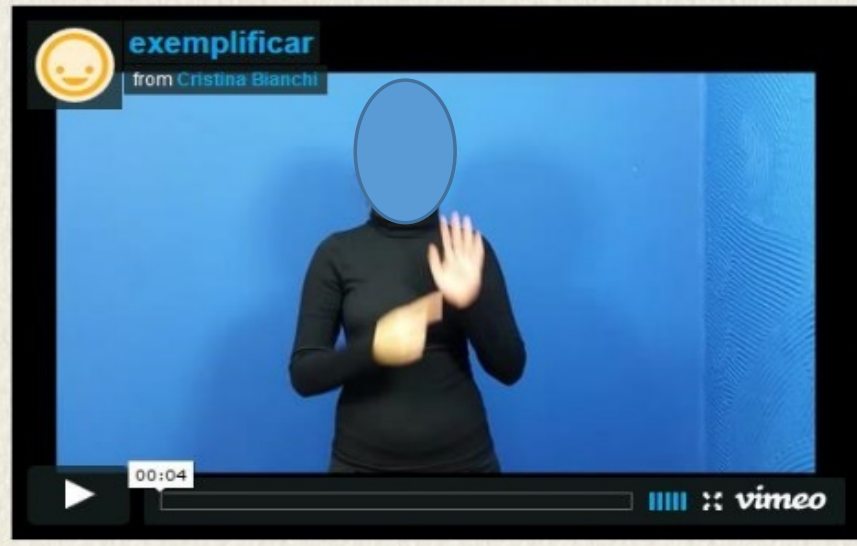

Equivalente: Mostrar

Ir para o contexto.

Remissiva em LSB- Ver citar e retratar

Fonte: https://glossariosemibilingue.wordpress.com/. Acesso em: 22 maio 2019.

Na Figura 12, podemos visualizar todas as informações que constam no verbete. Salientamos que, se o consulente desejar ir para o contexto, basta clicar em Ir para o contexto. Se desejar ir para a remissiva em LSB, basta clicar no termo que se encontra posicionado logo à frente da remissiva.

\section{Considerações finais}

Utilizamos neste trabalho a pesquisa bibliográfica, e ainda fizemos um levantamento de termos que já possuíam equivalentes em LSB. Para isso, compilamos termos do livro didático adotado na Escola Bilíngue Libras e Português escrito de Taguatinga-DF e constituímos o corpus da dissertação, a pesquisa bibliográfica. 
Procuramos, primeiramente, entender a relação do aluno com a aquisição do novo léxico da Língua Portuguesa para elaborarmos o glossário dos comandos das questões do livro didático da Língua Portuguesa adotado em sala de aula.

A metodologia da pesquisa-ação, segundo Engel (2000, p. 182), "procura unir a pesquisa à ação ou prática, isto é, desenvolver o conhecimento como parte da prática". Nossa pesquisa parte de observações realizadas dentro de salas de aula em que o aluno surdo não tem acesso linguístico ao livro didático. Por isso, por meio do glossário proposto, procuramos intervir no processo de ensino-aprendizagem do português como segunda língua, pois, ainda conforme Engel (2000, p. 182), a pesquisa-ação deve "intervir na prática de modo inovador já no decorrer do próprio processo de pesquisa e não apenas como possível consequência de uma recomendação na parte final do projeto". Com base nessas metodologias, fizemos alguns ajustes necessários à elaboração do glossário digital semibilíngue em Língua de Sinais Brasileira e Língua Portuguesa, porque trabalhamos com duas línguas diferentes, a primeira viso-espacial e a segunda oral.

Apoiamo-nos em princípios metodológicos e nas aplicações da terminologia propostos por Krieger e Finatto (2004, p. 226-227), “os produtos terminográficos, dicionários técnico-científicos, glossários e bancos de dados terminológicos, entre outros instrumentos de referência, refletem as relações teoria e prática no atendimento de necessidades sociais". Segundo essas autoras, a teoria proposta pela terminologia precisa levar em conta “os produtos terminográficos, dicionários técnico-científicos, glossários e bancos de dados terminológicos, entre outros instrumentos de referência, refletem as relações teoria e prática no atendimento de necessidades sociais".

Levando-se em conta a pesquisa apresentada neste texto, destacamos que o glossário semibilíngue digital em Língua de Sinais Brasileira é resultado de um árduo trabalho desenvolvido em parceria com os alunos do 9o ano da Escola Bilíngue Libras 
e Português Escrito. Nosso intuito foi produzir um material prático que possa auxiliar no ensino de português como segunda língua.

No âmbito escolar, nossos alunos o estão utilizando para a pesquisa dos verbos cujos significados desconhecem, e, quando encontram algum verbo fora do contexto do livro didático, nos questionam o porquê de não o encontrarem e pedem a ampliação de seu sentido. Além disso, alguns discentes do ensino médio solicitaram a criação de um glossário com a terminologia própria das disciplinas de história, geografia e biologia. Tal pedido nos fez crer que nosso trabalho, um glossário contextualizado, se configura como uma nova alternativa metodológica de aprender o português.

Fora do recinto escolar, também percebemos os resultados satisfatórios do uso de nosso glossário. Em agosto de 2018, no último levantamento que fizemos, já tínhamos mais de 6000 acessos feitos por diversas pessoas e de diversos países. Isso comprova que nosso modelo de glossário pode ser usado para o ensino.

Isso posto, concluímos que nosso protótipo de glossário semibilíngue para alunos surdos é um recurso didático eficaz para o ensino de Língua portuguesa. Ele pode e deve ser ampliado para outras áreas do conhecimento, uma vez que sua eficácia pôde ser comprovada pelos dados que apontaram o êxito do nosso trabalho.

\section{Referências bibliográficas}

BIDERMAN, M. T. C. Teoria linguística. São Paulo: Editora Martins Fontes, 2001a.

BIDERMAN, M. T. C. As ciências do léxico. In: ISQUERDO, A. N.; FINATTO, M. J. B. (org.). As ciências do léxico: lexicologia, lexicografia e terminologia. Rio Grande do Sul: UFRGS, 2001b. p. 13-22.

BRITO, L. F. Por uma gramática de línguas de sinais. Rio de Janeiro: Tempo brasileiro, 2010.

CEREJA, W. R.; MAGALHÃES, T. C. Português: linguagens. São Paulo: Atual, 2014. 
ENGEL, G. I. Pesquisa-ação. Educar, Curitiba, n. 16, 2000, p. 181-191. DOI https://doi.org/10.1590/0104-4060.214

FAULSTICH, E. Proposta metodológica para elaboração de léxicos, dicionários e glossários: modelos de ficha de terminologia. Brasília: UnB, 2001.

GOMES, C. A. B. de S. Proposta para o ensino de língua portuguesa como segunda língua: glossário semibilíngue digital em Língua de Sinais Brasileira e Língua Portuguesa. 300 f. Dissertação (Mestrado em Letras). Universidade Estadual de Montes Claros, Montes Claros, 2016.

Glossário semibilíngue digital em Língua de Sinais Brasileira e Português: comandos de questões do livro didático. In: GOMES, C. A. B. S. Proposta para o ensino de língua portuguesa como segunda língua: glossário semibilíngue digital em Língua de Sinais Brasileira e Língua Portuguesa. 300 f. Dissertação (Mestrado em Letras). Universidade Estadual de Montes Claros, Montes Claros, 2016. Disponível em: https://glossariosemibilingue.wordpress.com/. Acesso em: 30 set. 2016.

ISQUERDO, A. N.; FINATTO, M. J. B. (org.). As ciências do léxico. v. 4. Campo Grande: Editora UFMS, 2010.

KRIEGER, M. G.; FINATTO, M. J. B. Introdução à terminologia: teoria e prática. São Paulo: Contexto, 2004.

LIMA, V. L. S. Língua de sinais: proposta terminológica para a área de desenho arquitetônico. 2014. 272 f. Tese (Doutorado em Linguística Teórica e Descritiva) - Universidade Federal de Minas Gerais, Belo Horizonte, 2014.

NASCIMENTO, S. P. F. Representações lexicais da língua de sinais brasileira: uma proposta Lexicográfica. 2009. 290f. Tese (Doutorado em Linguística) - Universidade de Brasília, Brasília, 2009.

NASCIMENTO, S. P. F. Libras-LP/LP-Libras: os primeiros passos para a elaboração de repertórios terminográficos bilíngues que atendam às necessidades educacionais de aprendizes surdos. Simpósio iberoamericano de terminologia. Montevidéu. Ponencias resúmenes, 2006, v. 1, p. 37.

QUADROS, R. M.; KARNOPP, L. Língua de sinais brasileira: estudos linguísticos. Porto Alegre: Artmed, 2004. DOI https://doi.org/10.18309/anp.v1i16.560 
TRIPP, D. Pesquisa-ação: uma introdução metodológica. Educação e pesquisa. São Paulo, v. 31, n. 3, p. 443-466, set./dez. 2005. DOI https://doi.org/10.1590/S151797022005000300009 